\title{
Development of Propositions on Human Cognitive Abilities Matching Impacts on Accounting Job Performance
}

\author{
Hannah Ji and Lisa Hinson \\ University of Florida \\ Faculty mentor: Lisa Hinson, Fisher School of Accounting
}

\begin{abstract}
The purpose of this research paper is to analyze the matching factors between the human expectation of accounting job cognitive ability needed and the actual cognitive ability requirement of those jobs and how this relationship impacts job performance. First, based on the human information processing theory and previous research of cognitive ability analysis related to jobs, this paper proposes a research model to analyze the cognitive abilities' matching factors between human expectation and actual job requirements of accounting jobs. Secondly, seven propositions are developed based on this research model. Thirdly, an instrument is developed to quantitatively measure these matching factors on job performance. Finally, theoretical and practical implications associated with the accounting job design are also presented in this paper.
\end{abstract}

Keywords: accounting, job performance, cognitive abilities

\section{Introduction}

In the current era, accounting jobs involve complicated tasks and activities that require heightened cognitive activities by the accounting professionals. Furthermore, individual accounting professionals often approach these high mental workloads in different ways. Consequentially, accounting professionsal often create high mental workloads, and different individuals approach each task and activities.

Most of the accounting jobs involve a large number of cognitive tasks and activities. These jobs require high cognitive capabilities from the human side and may produce high human mental workloads. However, cognitive or mental abilities vary among individual job incumbents. Hence, the design of accounting jobs that match job requirements with human expectations on 
cognitive abilities may influence cognitive job performance (Wei and Salvendy, 2000; 2004). A good match on cognitive abilities may increase job performance (such as productivity) and human welfare (such as health, safety, motivation and satisfaction).

Most research on cognitive ability analysis on jobs focuses on cognitive task analysis with an emphasis at the task level. Wei and Salvendy (2000; 2004) developed a general cognitive task analysis system to capture a holistic view of cognitive abilities required by a variety of cognitiveoriented jobs. Ji and Salvendy (2019) also presented a cognitive-oriented task analysis method focusing on mobile cognitive ability analysis to further investigate accounting jobs. Campbell, Saner and Bunting (2016) presented a method to analyze cybersecurity jobs. However, these literatures did not study the impact of cognitive abilities on job performance in the cognitive domain for accounting jobs.

1. Furthermore, prior research only focused on some aspects of cognitive abilities in accounting jobs and did not study the match of cognitive ability requirements with human expectations (Dalton, Buchheit, and McMillan, 2014; Bagley, 2010 ; Lepistö, Järvenpää, Ihantola, and Tuuri, 2016; Long and Basoglu, 2016). Such a knowledge gap is an issue not only in the accounting field, but also in other professions. When this gap is filled, research on accounting jobs will become more applicable to the profession, rather than focusing on the theoretical aspects of accounting. Hence, the current research aims at investigating the cognitive ability matching impact on accounting job performance, with the goal of improving accounting job performance via job (re)design and changing potential employee's expectations. The matching factors of cognitive abilities refer to the match of job required cognitive abilities with human expectations.

\section{Literature Review}

Although cognitive abilities are important in many fields, human cognition is ever so important in the modern-day field of accounting. According to Ho and Rodgers (1993), cognitive abilities involve activities such as acquiring, storing, retrieving, and transforming information, but reflects more of an individual's level of skill, thereby changing throughout the individual's lifetime. Furthermore, cognitive abilities analyze the individual's ability to filter and process the source and form of financial information and to re-organize the information for decision-making. Thereby, the cognitive abilities an accountant brings to the workplace are a crucial component of 
the benefits reaped from hiring the individual. For example, Fuller and Kaplan (2004) revealed that accountants conducting audits use cognitive abilities such as information handling and learning for analytical and intuitive tasks. On the other hand, according to Long and Basoglu (2016), accuracy is important for accountants working on tax, and thereby requires these accountants to possess cognitive abilities of information searching and mental execution.

Specifically, there are three tracks in the accounting domain: audit, tax, and management or consulting. According to the American Institute of Certified Public Accountants (AICPA) (n.d.), each track has certain cognitive abilities associated with the specific accounting job. For example, the AICPA (n.d.) explains that a Staff Auditor works under the supervision of a Senior Auditor conducting financial audits, and thereby requires information searching and handling, communication, and learning cognitive abilities to successfully undertake the job. On the other hand, an Audit Manager holds more responsibilities, such as supervising Senior and Staff Auditors, reviewing paperwork, and maintaining client relationships. Thereby, Audit Managers require almost every cognitive ability mentioned in this paper: information searching and handling, mental planning and execution, monitoring, learning, communication, and environment. On a similar note, Bagley (2010) concurs by mentioning how most auditors are under the supervision of multiple superiors, thereby requiring cognitive abilities of communication and learning. According to the Public Company Accounting Oversight Board (PCAOB) (2013), the audit quality framework also requires auditors to exercise risk assessment, monitoring, information and communication, and control activities, which explicitly requires auditors to have cognitive abilities of information searching and handling, mental planning and execution, monitoring, learning, communication, and environment.

The AICPA (n.d.) also defines a Tax Staff as an accountant who works under the supervision of a Tax Manager, while engaging with clients, preparing tax returns, and conducting research. Consequentially, a Tax Staff would require cognitive abilities of information searching and handling, mental planning and execution, communication, and learning. Tax Managers also require almost every cognitive ability mentioned in this paper as their duties involve supervising Tax Senior and Staff, higher-level researching, and engaging with clients. Along the same lines, Rosenthal (2016) mentions how public opinion of tax accountants expects these professionals to help with tax compliance issues and prepare accurate tax returns, which consequentially leads to 
tax accountants' job requirements of cognitive abilities to include information searching and handling, mental planning and execution, communication, and environment. Roberts (1998) further elaborated by stating that the environment affects tax accountants' decision-making process, thereby implying that the job environment is an important factor for tax accountant's cognitive abilities.

As defined by the AICPA, Management Services/Consultants Staff work to engage with clients and are under the supervision of Managers and Seniors as well, thereby also requiring cognitive abilities of information searching and handling, communication, and learning.

Similarly, a Management Services/Consulting Manager oversee operational budgets and analyze operational and internal control procedures, projects, and even departments of corporations, thereby requiring almost all the cognitive abilities mentioned in this paper, such as information searching and handling, mental planning and execution, monitoring, learning, communication, and environment.

2. In general, accounting professionals need certain cognitive abilities to properly perform their jobs, but their expectation of what cognitive abilities are required of the job may be different from the actual requirement of cognitive abilities the job entails. According to Dalton et al. (2014), accounting students' expectations of cognitive abilities required by audit and tax jobs often differ from accounting professionals' opinion of those same jobs. In a sense, the cognitive abilities expected by an individual before undertaking the job and afterwards can have a mismatch, thereby creating job dissatisfaction and other inefficiencies. Thereby, avoiding this mismatch can increase the efficiency and relevancy of the research on the accounting profession.

\section{Research Model}

The human information processing theory was developed by Salvendy and Knight (1998) to create an information processing model of human operators. This theory was further applied by Wicken $(1987,1997)$ to develop a resource allocation model, which is a general frame when analyzing human information processing with a focus on attention and memory. Meyer and Kieras (1997) developed a framework of human information processing for cognitive task analysis based on applying human information processing theory. This framework provides an executive process interactive control for characterizing human performance in multiple tasks in a variety of conditions. By applying human information processing theory and modifying 
Wickens' resource allocation model $(1987,1997)$ in the breadth and depth,. Wei and Salvendy (2000) developed a human-centered cognitive performance (HCCP) model to dynamically capture the cognitive attributes based on seven functional modules, two resource modules and two affect modules. Ji and Salvendy (2019) applied this HCCP model to characterize the mobile cognitive-oriented attributes for accounting jobs. They developed a mobile cognitive task analysis (MCTA) model based on the human information processing theory. The MCTA model identifies the cognitive abilities that can be enhanced by mobile devices when performing cognitive-intensive jobs.

Based on human information processing theory and research related to cognitive ability analysis on jobs, this paper proposes a research model to capture the cognitive abilities' matching factors and their impacts on job performance. The cognitive abilities' matching factors are assessed based on the match of job required cognitive abilities with human expectation from accounting jobs. As depicted in Figure 1, the matching factors of cognitive abilities will positively affect the job satisfaction, which in turn will positively affect the expected job performance. The cognitive abilities factors have two classifications: primary factors (information searching, information handling, mental planning, mental execution and monitoring) and support factors (learning and communication).

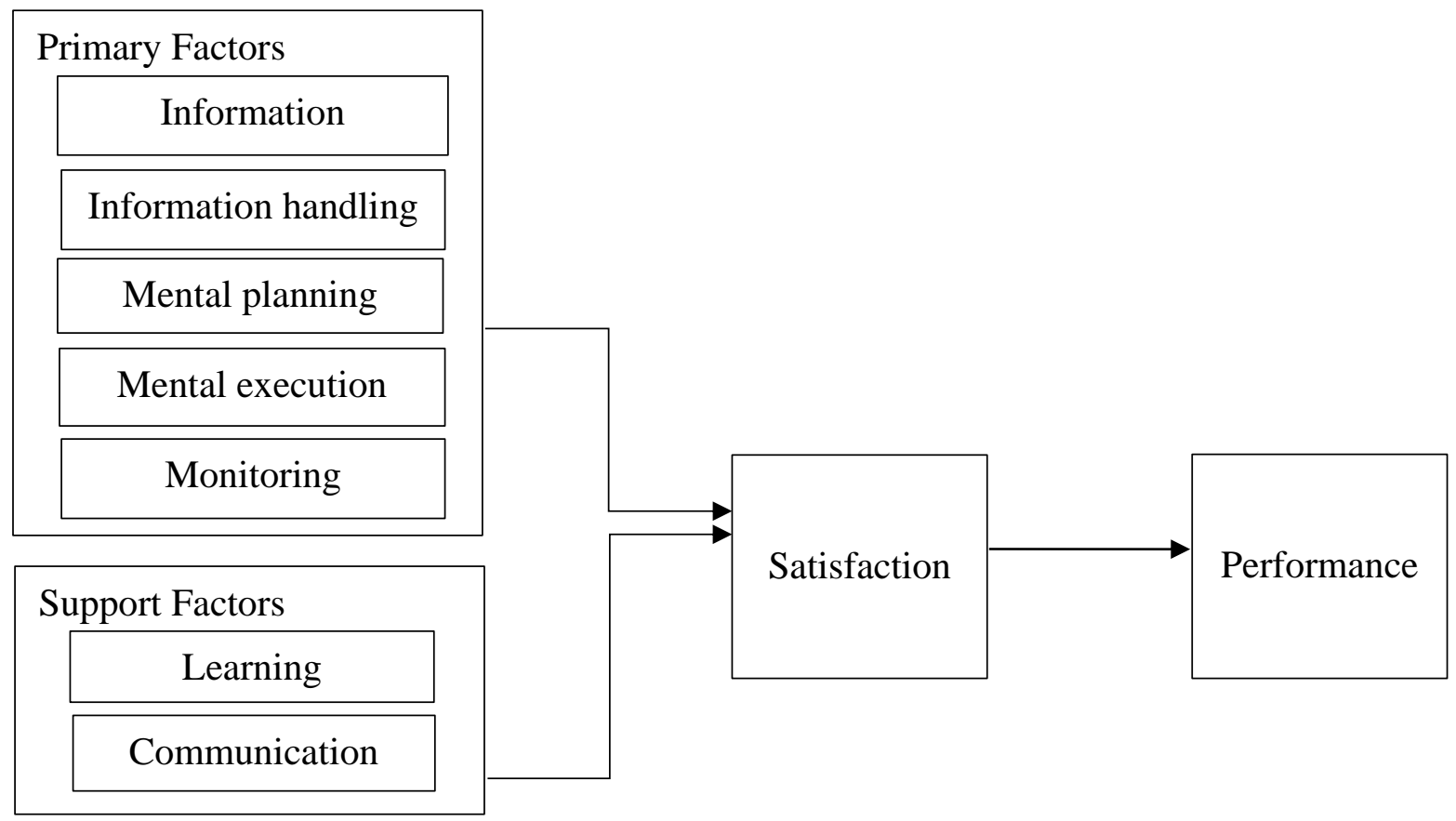

Figure 1. A Research Model of Cognitive Ability Impacts on Accounting Jobs Performance 


\section{Propositions}

Information searching ability is an essential cognitive ability required by accounting jobs (PCAOB, 2013; Rosenthal, 2016; Brandas et al., 2015; Lepistö, 2016; Gupta and Marshall, 2010), and thereby, a higher match between the expectation of an individual with regards to the information searching ability required of an accounting job with the actual job requirements of that job will most likely result in higher job satisfaction and motivation, and in turn result in higher job performance. This match, while important, is often lacking in the accounting profession.

Proposition 1 on Information Searching Ability:

The high the A greater match of job requirement with human expectation for information searching ability will result in high satisfaction on accounting jobs.

Information handling ability is also an essential cognitive ability required by accounting jobs (PCAOB, 2013; Rosenthal, 2016; Fuller and Kaplan, 2004; Long and Basoglu, 2016), and thereby, a higher match between the expectation of an individual with regards to the information handling ability required of an accounting job with the actual job requirements of that job will most likely result in higher job satisfaction, and in turn result in higher job performance:

\section{Proposition 2 on Information Handling Ability:}

The high the A greater match of job requirement with human expectation for information handling ability will result in high satisfaction on accounting jobs

Mental planning is a cognitive ability crucial to accountants for various tasks in their daily routine (Long and Basoglu, 2016; PCAOB, 2013), and thereby, a higher match between the expectation of an individual with regards to the mental planning ability required of an accounting job with the actual job requirements of that job will most likely result in higher job satisfaction, and in turn result in higher job performance:

Proposition 3 on Mental Planning Ability:

The high theA greater match of job requirement with human expectation for mental planning ability will result in high satisfaction on accounting jobs 
Mental execution ability is a crucial component of promoting accounting job satisfaction and motivation, for this ability is a very important cognitive abilities job requirement (Long and Basoglu, 2016; PCAOB, 2013; Rosenthal, 2016), and thereby, a higher match between the expectation of an individual with regards to the mental execution ability required of an accounting job with the actual job requirements of that job will most likely result in higher job satisfaction and motivation, and in turn result in higher job performance:

Proposition 4 on Mental Execution Ability:

The high the A greater match of job requirement with human expectation for mental execution ability will result in high satisfaction on accounting jobs

Monitoring ability is a cognitive ability especially important to senior accountants, according to the AICPA. However, this ability is most definitely a crucial requirement for any accounting job (AICPA, n.d.; PCAOB, 2013; Rosenthal, 2016), and thereby, a higher match between the expectation of an individual with regards to the monitoring ability required of an accounting job with the actual job requirements of that job will most likely result in higher job satisfaction, and in turn result in higher job performance:

Proposition 5 on Monitoring Ability:

The high the A greater match of job requirement with human expectation for monitoring ability will result in high satisfaction on accounting jobs

The learning ability is one of the most prominent cognitive abilities needed for accounting jobs, especially for beginning professionals (PCAOB, 2013; Rosenthal, 2016; AICPA), and thereby a higher match between the expectation of an individual with regards to the learning ability required of an accounting job with the actual job requirements of that job will most likely result in higher job satisfaction and motivation, and in turn result in higher job performance:

\section{Proposition 6 on Learning Ability:}

The high the A greater match of job requirement with human expectation for learning ability will result in high satisfaction on accounting jobs

The cognitive ability of communication is one of the most important cognitive abilities required of accounting jobs (Levy, 2017; Rosenthal, 2016; AICPA; PCAOB, 2013), and thereby a higher 
match between the expectation of an individual with regards to the communication ability required of an accounting job with the actual job requirements of that job will most likely result in higher job satisfaction and motivation, and in turn result in higher job performance:

\section{Proposition 7 on Communication Ability:}

The high the A greater match of job requirement with human expectation for communication ability will result in high satisfaction on accounting jobs

An instrument was developed to quantitatively assess the match between the key cognitive abilities required by accounting jobs with the human job applicants' expectation of cognitive abilities needed by accounting jobs. We borrowed items from Wei and Salvendy (2000), Davis and Bagozzi (1992), Susarla, Barua and Whinston (2003) and Venkatesh et al. (2003). The questionnaire was designed using the five-point Likert scale ranging from 1 (strongly disagree) to 5 (strongly agree).

\section{Implication, Future Research and Conclusion}

This paper aims at investigating the matching factors between the human expectation of job cognitive ability needed and the actual cognitive ability requirement of accounting jobs. It also investigates the impact of these matching factors on human job performance. A research model was developed based on the human information processing theory and previous research of cognitive ability analysis related to jobs to analyze these matching factors and their impacts on job performance. Seven propositions were also presented based on this research model. The propositions developed in this paper provide insight into how accounting job designs can be improved to provide higher levels of job satisfaction and better human performance for accounting employees.

Moreover, an instrument was developed to measure these matching factor and job satisfaction and performance. The questions in this survey asks for the match of human cognitive abilities the subject expected to need for the specific accounting job they are analyzing with the actual job requirement of human cognitive abilities for that specific accounting job. 
The future research will be conducted to empirically test this research model by collecting data from accounting job performers. The differences of these propositions can also be tested between audit and tax tracks.

\section{Referencess}

AICPA (n.d.) Positions in Public Accounting, American Institute of Certified Public Accountants. Retrieved from https://www.aicpa.org/career/careerpaths/publicaccounting.html

Bagley, P.L. (2010) Negative affect: A consequence of multiple accountabilities in auditing. Auditing: A Journal of Practice and Theory, 29(2), 141-157.

Brandas, C., Megan, O. \& Didraga, O. (2015). Global perspectives on accounting information systems: mobile and cloud approach. Procedia Economics and Finance, 20, 88-93.

Campbell, S.G., Saner, L.D. and Bunting, M.F. (2016) 'Characterizing cybersecurity jobs: applying the cyber aptitude and talent assessment framework. Proceedings of the Symposium and Bootcamp on the Science of Security, pp.25-27.

Dalton, D. W., Buchheit, S., \& McMillan, J. J. (2014) Audit and tax career paths in public accounting: an analysis of student and professional perceptions. Accounting Horizons, 28(2), 213-231.

Davis, F.D., \& Bagozzi, R.P. (1992) Extrinsic and intrinsic motivation to use computers in the workplace. Journal of Applied Social Psychology, 22(2), 1111-1132.

Fuller, L. R., and S. E. Kaplan. 2004. A note about the effect of auditor cognitive style on task performance. Behavioral Research in Accounting 16, 131-143.

Gupta, S., \& Marshall, L. L. (2010). Congruence between entry-level accountants' required competencies and accounting textbooks. Academy of Educational Leadership Journal, 14(1), 1-12.

Ji, Hannah \& Salvendy, G. (2019), Characterizing mobile-enhanced cognitive abilities: implications for accounting jobs. International Journal of Mobile Communications, 12(3).

Levy, H. B. (2017). Distinguishing agreed-upon procedures from consulting engagements and reports. CPA Journal, 87(7), 62-64.

Lepistö, L., Järvenpää, M., Ihantola, E. and Tuuri, I. (2016) The tasks and characteristics of management accountants: insights from Finnish recruitment processes. Nordic Journal of Business, 65(3-4), 76-82.

Long, J.H. and Basoglu, K.A. (2016) 'The Impact of Task Interruption on Tax Accountants' Professional Judgment. Accounting, Organizations and Society, 55(1), 96-113.

Meyer, D.E. and Kieras, D.E. (1997). A computational theory of executive cognitive processes and multiple-task performance, Part I: Basic mechanisms. Psychological Review, 104(1), 3-65.

Pcaob Standing Advisory Group Meeting (2013). Discussion-Audit Quality Indicators, Public Company Accounting Oversight Board. Retrieved from https://pcaobus.org/news/events/documents/05152013_sagmeeting/audit_quality_indicators.pdf 
Roberts, M. L. (1998). Tax accountants' judgment/decision-making research: A review and synthesis. The Journal of the American Taxation Association, 20(1), 78-121.

Rosenthal, L. (2016). Evaluating the Demand for Tax Professionals: Tax Accountants or Tax Attorneys (Order No. 10583068). Available from ProQuest Dissertations \& Theses Global. (1879728858).

Salvendy, G. and Knight, J.J. (1988). Psychomotor performance and information processing. In S. Gael (Eds.), The Job Analysis Handbook for Business, Industry, and Government, Vol I (pp.630-695). New York: John Wiley \& Sons.

Susarla, A., Barua, A. \& Whinston, A.B. (2003) Understanding the service component of application service provision: An empirical analysis of satisfaction with ASP Services. MIS Quarterly, 27 (1), $91-123$

Venkatesh, V., Morris, M.G., Davis, G.B. and Davis, F.D. (2003) User acceptance of information technology: Toward a unified view. MIS Quarterly, 27(3), 425- 478.

Wei, J. \& Salvendy, G. (2000), Development of the Purdue cognitive job analysis methodology. International Journal of Cognitive Ergonomics, 4(4), 277-296.

Wei, J. \& Salvendy, G. (2004), The Cognitive task analysis methods for job and task design: review and reappraisal. Behavior and Information Technology, 23(4), 273-299.

Wickens, C.D. (1987). Information processing, decision-making, and cognition. In G. Salvendy (Eds), Handbook of human factors, Chapter 2.2 (pp.72-107). New York: John Wiley \& Sons.

Wickens, C.D. and Carswell, C.M. (1997). Information processing. In G. Salvendy (Eds), Handbook of human factors ( $2^{\text {nd }}$ Ed.), Chapter 4. New York: John Wiley \& Sons. 